\title{
Do countries belonging to the same region suggest the same growth enhancing variables? Evidence from selected South Asian countries
}

\author{
Arusha Cooray a,b ${ }^{\mathrm{a}}$, Antonio Paradiso ${ }^{\mathrm{c}, *}$, Francesco Giovanni Truglia $^{\mathrm{d}}$ \\ a School of Economics University of Wollongong, Wollongong, Australia \\ ${ }^{b}$ Centre for Applied Macroeconomic Analysis, Australian National University, Australia \\ ' University of Venice Ca' Foscari, Venice, Italy \\ d Italian National Institute of Statistics (ISTAT), Rome, Italy
}

\section{A R T I C L E I N F O}

\section{Article history:}

Accepted 5 June 2013

Available online $\mathrm{xxxx}$

\section{JEL classification}

040

C22

053

Keywords:

Homogeneity

Country specific time-series

South Asian countries

\begin{abstract}
A B S T R A C T
We investigate the growth enhancing variables in a group of countries belonging to the same geographical area namely, India, Sri Lanka, Pakistan and Bangladesh over the period 1960-2010. We find that this "homogeneity" does not necessarily imply that countries have the same growth enhancing variables due mainly to differences in institutions and policies. Our result suggests that time-series econometrics are preferable to identify the growth drivers for a country accurately.
\end{abstract}

(c) 2013 Elsevier B.V. All rights reserved.

\section{Introduction}

One of the most influential cross-country studies on economic growth is the study of Mankiw et al. (1992), hereafter MRW. The authors performed an empirical evaluation of an extended version of the Solow-Swan growth model by incorporating human capital. They found that the augmented Solow-Swan model fitted the data well and yielded plausible estimates of the elasticity of output with respect to capital. Numerous authors have since used the MRW framework to study the significance of additional factors on growth (Durlauf and Quah, 1999). Some authors, such as Durlauf and Johnson (1995) and Dinopoulos and Thompson (1999), have questioned these results. The first authors maintain that heterogeneity among various groups of countries should be considered (i.e., grouping the countries in homogenous groups). The second authors present the Schumpeterian view of the growth model, where the distribution of a country's technology depends on their R\&D expenditures, and maintain that differences in technology should be imposed in estimations for greater accuracy in results. Evidence of such (technological) heterogeneity may also be found in Durlauf et al. (2001). Moreover, evidence of parameter heterogeneity using different

\footnotetext{
* Corresponding author.

E-mail addresses: arusha.@uow.edu.au (A. Cooray), anto_paradiso@hotmail.com (A. Paradiso), truglia@istat.it (F.G. Truglia).
}

statistical methodologies has been also found by Canova (2004) and Desdoigts (1999).

Our research focuses on a group of South Asian countries (India, Sri Lanka, Pakistan and Bangladesh). In the literature, the South Asian countries have been considered similar and homogeneous (and for this reason considered suitable to study using panel estimation techniques) based on some macro stylized facts (Narayan et al., 2010; Jongwanich and Kohpaiboon, 2013), on common history and historical relations (Rizavi et al., 2010), and simply on international regional divisions (Jalles, 2012). We show, employing appropriate statistical tests, that despite apparent homogeneity in countries belonging to the same geographical area with similar technology, and apparent similar macro stylized facts, there could be other sources of heterogeneity such as different political, legal and economic institutions, and national policies that may change the forces driving growth in countries. This makes time-series estimation technique more suitable to precisely detect growth driving variables. Using country-specific time-series estimation, we show that growth enhancing variables are effectively different for these countries. Luintel et al. (2008) argue that panel regressions ignore significant cross country differences and suffer from problems associated with data pooling in the absence of balanced growth. Additionally, unless parameter heterogeneity is dealt with, estimates are biased and inconsistent yielding inaccurate conclusions for countries. Therefore, we believe that in the absence of a similarity among countries, time 
series estimation is superior to cross-country/panel estimation (where data are available) to detect precise growth drivers for countries. ${ }^{1}$

Section 2 presents country characteristics for the four South Asian countries selected for our analysis, illustrating their apparent homogeneity and showing their dissimilarities using appropriate statistical tests. Section 3 presents the model. Section 4 illustrates the methodological aspects and data. Section 5 explains the results and Section 6 concludes.

\section{Country characteristics}

This study considers four South Asian countries - India, Sri Lanka, Pakistan and Bangladesh - because this group is considered homogeneous by the literature (Mallik and Chowdhury, 2001) and stylized facts seem to confirm this. Table 1 shows that these countries are very similar in terms of their economic performance (GDP growth and inflation rates), economic characteristics (capital accumulation measured by investment to GDP ratio, skills measured by average years of schooling, ${ }^{2}$ and structure of output measured by sectoral contributions to GDP), and technology (measured as investment per employee $^{3}$ ), with the exception of Sri-Lanka which shows higher capital accumulation, education levels, capital per employee, and lower agricultural sector contribution to GDP.

The similarity among countries can be investigated through a cross-sectional dependence test applied for the period 1975-2010. ${ }^{4}$ The cross-sectional dependence is described as the interaction between cross-sectional units (i.e., households, firms and states as in our case) and has been widely discussed in the spatial literature. Intuitively, dependence across "space" can be regarded as the counterpart of serial correlation in time series; it could arise from unobservable common factors or common shocks. If there exists cross-correlation, then the countries move together (driven by common factors) and we can say that have some similarities. When the time-series dimension $T$ of the panel is larger than the cross sectional dimension $N$, which is the case in our data, one may use the LM test, developed by Breusch and Pagan (1980). The Breusch and Pagan [BP] (1980) test statistic is based on the squared pair-wise correlation of the residual series. The BP statistic tests the null of zero correlation using the following Lagrange multiplier statistic:

$$
\begin{aligned}
& C D_{L M}=T \sum_{i=1}^{N-1} \sum_{j=i+1}^{N} \hat{\rho}_{i j}^{2} \\
& \text { with } \hat{\rho}_{i j}=\hat{\rho}_{j i}=\frac{\sum_{t=1}^{T} e_{i j} e_{j t}}{\left(\sum_{t=1}^{T} e_{i j}^{2}\right)^{1 / 2}\left(\sum_{t=1}^{T} e_{j t}^{2}\right)^{1 / 2}}
\end{aligned}
$$

where $\hat{\rho}_{i j}^{2}$ is the sample estimate of the pair-wise correlation of the residuals. BP show that under the null hypothesis of no cross sectional dependence the $C D_{L M}$ statistic is asymptotically distributed as chi-squared with $N(N-1) / 2$ degrees of freedom with $N$ fixed and as $T$ approaches to infinity.

\footnotetext{
${ }^{1}$ See Coakley et al. (2006). This is justified by Luintel et al. (2008) who use the same approach as us by applying country by country time-series analyses. Also see Greiner et al. (2005), King and Ramlogan (2008) and Rao et al. (2011) for advantages of time-series methods.

2 Average years of schooling is the years of formal schooling received, on average, by adults over age 15. (Data Source: Barro-Lee (2010)).

${ }^{3}$ We use differences in investment ratio (normalized with respect to US) as a proxy measure of the technology difference among countries. A large difference in invest ment per employee indicates a large difference in capital intensities and, presumably, in technologies (Pianta, 1995). The similarity in technological level among Bangladesh, India, and Pakistan is indirectly confirmed by Dinopoulos and Thompson (1999) who sustain that the technology level in each country is strongly positively related to its human capital level.

${ }^{4}$ We thank an anonymous referee for having suggested the usage of this test.
}

To evaluate the presence of cross sectional dependence we use two alternative models (Eqs. (2) and (3)) over the period 1975-2010:

$y_{i t}=\alpha_{i}+\beta_{i}^{\prime} x_{i t}+\varepsilon_{i t}$,

where $y_{i t}=$ GDP growth rate of the country $i ; x_{i t}=4 \times 1$ vector of the following variables: Inv/GDP, $\Delta \ln$ (Schooling), inflation, $y_{i t-1}$. The intercept $\alpha_{i}$ and the slope coefficient $\beta_{i}$ are allowed to be heterogeneous across $i$ (i.e., an OLS regression in the time series dimension of $y_{i t}$ on an intercept and $x_{i t}$ is performed for each cross section $i$, separately.);

$y_{i t}=\alpha_{i}+\beta^{\prime} x_{i t}+\varepsilon_{i t}$,

where the intercept is allowed to vary across units to account for country specific time invariant features such as unobservable and unmeasurable factors such as culture, norms, social beliefs, geographic characteristics, etc. Both models do not reject the null hypothesis with a p-value of 0.096 and 0.209 for Eqs. (2) and (3), respectively.

Another test used in literature to determine if two or more groups are significantly different is Levene's test [LT] (1960). ${ }^{5}$ More precisely, this test is used to examine if $k$ groups have equal variances. If the variance of the groups differs significantly, then this provides strong evidence that groups are not selected from an identical population and are not similar. LT is an alternative to the Bartlett test. The LT is less sensitive than the Bartlett test to departures from normality. ${ }^{6}$ Given a variable $Y$ with sample size $N$ divided into $k$ subgroups (where $N_{i}$ is the sample size of the ith subgroup), the LT is defined as

$W=\frac{(N-k) \sum_{i=1}^{k} N_{i}\left(\bar{Z}_{i .}-\bar{Z}_{. .}\right)^{2}}{(k-1) \sum_{i=1}^{k} \sum_{j=1}^{N_{i}}\left(Z_{i j}-\bar{Z}_{i .}\right)^{2}}$

where $Z_{i j}=\left|Y_{i j}-\tilde{Y}_{i}\right|$ with $\tilde{Y}_{i}$ indicating the median of the ith subgroup, $\bar{Z}_{i}$. are the group means of the $Z_{i j}$, and $\bar{Z}$.. is the overall mean of the $Z_{i j}$. The definition based on the median and bootstrapping resampling is preferable since this version is more robust for the significance level under any kind of distribution and combination of sample sizes (Parra-Frutos, 2009). The null hypothesis is that the groups have equal variances.

We apply the LT test to the group of four countries (BGD, SLK, PAK, IND) to the period 1975-2010 and for the same variables considered in the BP test, namely, GDP growth rate $\left(L T_{G D P}\right)$, inflation $\left(L T_{I N F L}\right)$, $\operatorname{Inv} / G D P\left(L T_{I N V / G D P}\right)$, and $\Delta \ln ($ Schooling $)\left(L T_{\Delta \ln (S C H)}\right)$. The $L T_{G D P}$ exhibits a p-value of 0.07 and we reject the null at the $10 \%$ significance level; $L T_{I N F L}$ does not reject the null ( $\mathrm{p}$-value $=0.13$ ), whereas both $L T_{I N V / G D P}$ and $L T_{\triangle \ln (S C H)}$ reject the null (p-value $<0.01$ ). Hence, only inflation exhibits homogeneity among the four South Asian countries.

Based on these tests, we can therefore conclude that there is evidence against the hypothesis that these countries move together with respect to a group of variables identifying economic characteristics of a country, suggesting dissimilarity among the countries. For this reason, time-series estimation techniques appear more suitable ${ }^{7}$ compared to panel data techniques to detect growth enhancing variables and discuss policies affecting growth.

\footnotetext{
${ }^{5}$ Plourde and Watkins (1998) applied Levene's test to investigate whether the behavior of oil prices changed in the 1980s and became more similar to that of other commodities. Examples of application of this test in economic growth studies are Starke et al. (2008) and Jakobi and Teltemann (2009).

${ }^{6}$ Statistical tests conducted on our dataset show that our data are not normal. Results are available from the authors upon request.

${ }^{7}$ When $T$ is large, one can allow for heterogeneity by estimating a separate timeseries equation for each unit (Coakley et al., 2006).
} 
Table 1

Economic characteristics of the countries under study.

Source: World Development Indicators.

\begin{tabular}{|c|c|c|c|c|c|c|c|c|}
\hline & \multicolumn{2}{|c|}{$\begin{array}{l}\text { Economic performance } \\
\text { (average over the } \\
\text { period 1975-2010) }\end{array}$} & \multirow{2}{*}{$\begin{array}{l}\text { Capital accumulation } \\
\text { (average over the } \\
\text { period 1975-2010) } \\
\text { Inv/GDP }\end{array}$} & \multirow{2}{*}{$\begin{array}{l}\text { Education } \\
\text { (value at the end of 2010) } \\
\text { Schooling }\end{array}$} & \multirow{2}{*}{$\begin{array}{l}\text { Capital intensity } \\
\text { (average over the period } \\
\text { 2000-2010; US = 100) } \\
\text { Inv/empl }\end{array}$} & \multicolumn{3}{|c|}{$\begin{array}{l}\text { Structure of GDP } \\
\text { (in 2010) }\end{array}$} \\
\hline & GDP growth ${ }^{\mathrm{a}}$ & $\operatorname{Infl}^{\mathrm{a}}$ & & & & Agr. & Ind. & Serv. \\
\hline Bangladesh & 4.46 & 8.42 & 17.87 & 5.79 & 1.78 & 18.8 & 28.5 & 52.7 \\
\hline India & 5.91 & 7.41 & 22.80 & 5.13 & 2.27 & 19 & 26.3 & 54.7 \\
\hline Pakistan & 5.11 & 9.87 & 18.62 & 5.59 & 2.98 & 21.2 & 25.4 & 53.4 \\
\hline Sri-Lanka & 4.96 & 10.99 & 25.74 & 11.07 & 5.37 & 12.8 & 29.4 & 57.8 \\
\hline
\end{tabular}

a Average values over the period 1975-2010; Agr. = Agriculture sector; Ind. = Industrial sector; Serv. = Services sector.

\section{The model}

The formulation used is a simplification of the MRW model employed by Senhadji (2000), Rao and Hassan (2012b), and Kumar and Pacheco (2012):

$Y_{t}=A_{t} K_{t}^{\alpha}\left(H_{t} \cdot L_{t}\right)^{1-\alpha}$

where $Y=$ output; $A=$ stock of knowledge; $K=$ capital; $H=$ human capital index; $L=$ total employment; and $\alpha=$ elasticity of output with respect to capital.

The intensive form of Eq. (5) is:

$y_{t}=A_{t} k_{t}$

where $y=(Y / H \cdot L)$ and $k=(K / H \cdot L)$. In Eq. (6) the variables are expressed in per worker terms adjusted for skill.

We assume, that the stock of knowledge $A_{t}$ evolves over time $t$ as follows:

$A_{t}=A_{0} e^{\tau_{t}+v_{t} \cdot T}$

where $A_{0}$ is the initial stock of knowledge and $\tau$ and $v$ are variables capturing level and growth effects, respectively. ${ }^{8} \mathrm{Eq}$. (7) can be further extended by assuming that $\tau$ and $v$ are functions of other variables (see Rao, 2010 and Casadio et al., 2012, among others):

$\tau_{t}=\phi_{1} s_{t}+\phi_{2} s_{t}^{2}+\delta z_{t}$

$v_{t} \cdot T=\left(\gamma_{1}+\gamma_{2} x_{t}\right) \cdot T$

where $\tau$ is assumed to be non-linear in $s$ and linear in $z$. For Eq. (8) to make sense $\phi_{1}>0$ and $\phi_{2}<0$, so that the $s$ variable has its maximum effect when $s=-0.5\left(\phi_{1} / \phi_{2}\right)$. This variable, prior to reaching its maximum effect, increases at a decreasing rate. Each additional unit of $s$ contributes less and less to the level of output. For example, a variable which may exhibit non-linear effects is trade openness. Kholi and Singh (1989) for instance, show evidence of non-linearities in the relationship between exports and growth. $v$ is a function of variables with growth effects but ignored $\left(\gamma_{1}\right)$ and known variables $(x)$ that have to be identified. $T$ is a time trend.

With these modifications the production function (6) will be:

$y_{t}=A_{0} e^{\left[\phi_{1} s_{t}+\phi_{2} s_{t}^{2}+\delta z_{t}+\left(\gamma_{1}+\gamma_{2} x_{t}\right) \cdot T\right]} k_{t}^{\alpha}$

$\therefore \ln y_{t}=\ln A_{0}+\phi_{1} s_{t}+\phi_{2} s_{t}^{2}+\delta z_{t}+\gamma_{1} \cdot T+\gamma_{2} x_{t} \cdot T+\alpha \ln k_{t}$

\footnotetext{
${ }^{8}$ In steady state, when $\Delta \ln k \rightarrow 0$ and all differences go to zero (Sala-i-Martin, 1994), the steady state growth rate (SSGR) is equal to $S S G R=\Delta \ln A=v_{t-1}$. This way, $v$ captures growth effects. It is easy to show this. If we insert Eq. (7) into Eq. (6) and taking the logarithm, we obtain $\ln y_{t}=\ln A_{0}+\tau_{t}+v_{t} \cdot T+\alpha \ln k_{t}$. If we take the first difference we have

$\Delta \ln y_{t}=\Delta \tau_{t}+v_{t} \cdot T-v_{t-1} \cdot(T-1)+\alpha \Delta \ln k_{t} \Rightarrow \Delta \ln y_{t}$ $=\Delta \tau_{t}+\Delta v_{t} \cdot T+v_{t-1}+\alpha \Delta \ln k_{t} \Rightarrow S S G R=v_{t-1}$
}

\section{Data and methodology}

All data are drawn from the World Development Indicators with the exception of the average years of schooling (data source: Barro and Lee, 2010). The data cover the 1960-2010 period (with the exception of India and Sri-Lanka for which the data sample is from 1970 to 2010). Our selected growth-enhancing variables are: a time trend $(T( \pm))$, foreign direct investment to GDP (FDIRAT $( \pm))$, trade openness measured by the ratio of import plus export to $\operatorname{GDP}(\operatorname{TRADE}( \pm)),{ }^{9}$ ratio of current government expenditure to GDP $(G R A T( \pm))$, ratio of private investment to GDP $(\operatorname{IRAT}(+))$, ratio of official development assistance and official aid received to GDP $(\operatorname{ODARAT}( \pm))$, ratio of M2 to GDP $(M 2 R A T(+))$, inflation rate $(\operatorname{INFL}(-))$, and ratio of workers' remittances to GDP $($ WRRAT $(+))$. The expected sign of the coefficients are in parentheses. The literature shows that IRAT has a positive effect on economic growth. As increased financial sector development promotes economic growth, M2RAT is expected to have a positive effect on growth (King and Levine, 1993). The South Asian economies are remittance dependent economies and the literature in general, shows a positive effect of remittances on growth. ${ }^{10}$ Inflation increases price variability adversely affecting growth (Barro, 1996). Studies show that the effect of FDI and trade on economic growth depends on the type of trade policy adopted by a country (Balasubramanyam et al., 1996), level of human capital in a country (Borensztein et al., 1998) among other factors. Therefore these variables could have a positive or negative effect on growth. The effect of government expenditures and openness depend mainly on the quality of institutions and governance, as we will discuss in Section 5. Accordingly, the coefficient on GRAT could be positive or negative. Similarly the effects of foreign aid on growth could be positive or negative depending on the effectiveness of the government in channeling these aid flows into public expenditure programs and economic policy (Burnside and Dollar, 2000; Roberts, 2003). As a preliminary step, we investigate the unit root properties of the variables using the ADF and DF-GLS tests. The results are reported in Table $1 \mathrm{~A}$ in Appendix A. The null hypothesis of a unit root cannot be rejected for the levels of all the variables. In addition, we test for the null of a unit root in the first differences, which can be rejected at the $1 \%$ significance level, with the exception of $\Delta \ln k(5 \%)$ for Bangladesh, Sri-Lanka and India. The evidence from the unit root tests indicates that all variables can be characterized as exhibiting a unit root process. Since all series are I(1), it is legitimate to investigate the existence of a cointegrating relation. We use the Dynamic OLS (DOLS) estimator for our empirical estimation of the long-run relation (Eq. (11)). The DOLS deals with the problem of second-order asymptotic bias arising from serial correlation and endogeneity and is asymptotically efficient (Saikkonen, 1991). In addition, DOLS performs better in finite samples

\footnotetext{
${ }^{9}$ According to Bergheim (2008), the best measure of openness is the time series of the trade share. That is the average share of exports and imports to GDP. Nominal variables are used to construct the openness measure.

10 See Cooray (2012). Rao and Hassan (2012a) however, show that the direct effects of remittances on growth are insignificant but evidence of small indirect effects.
} 
Table 2

DOLS estimates for the four South Asian countries.

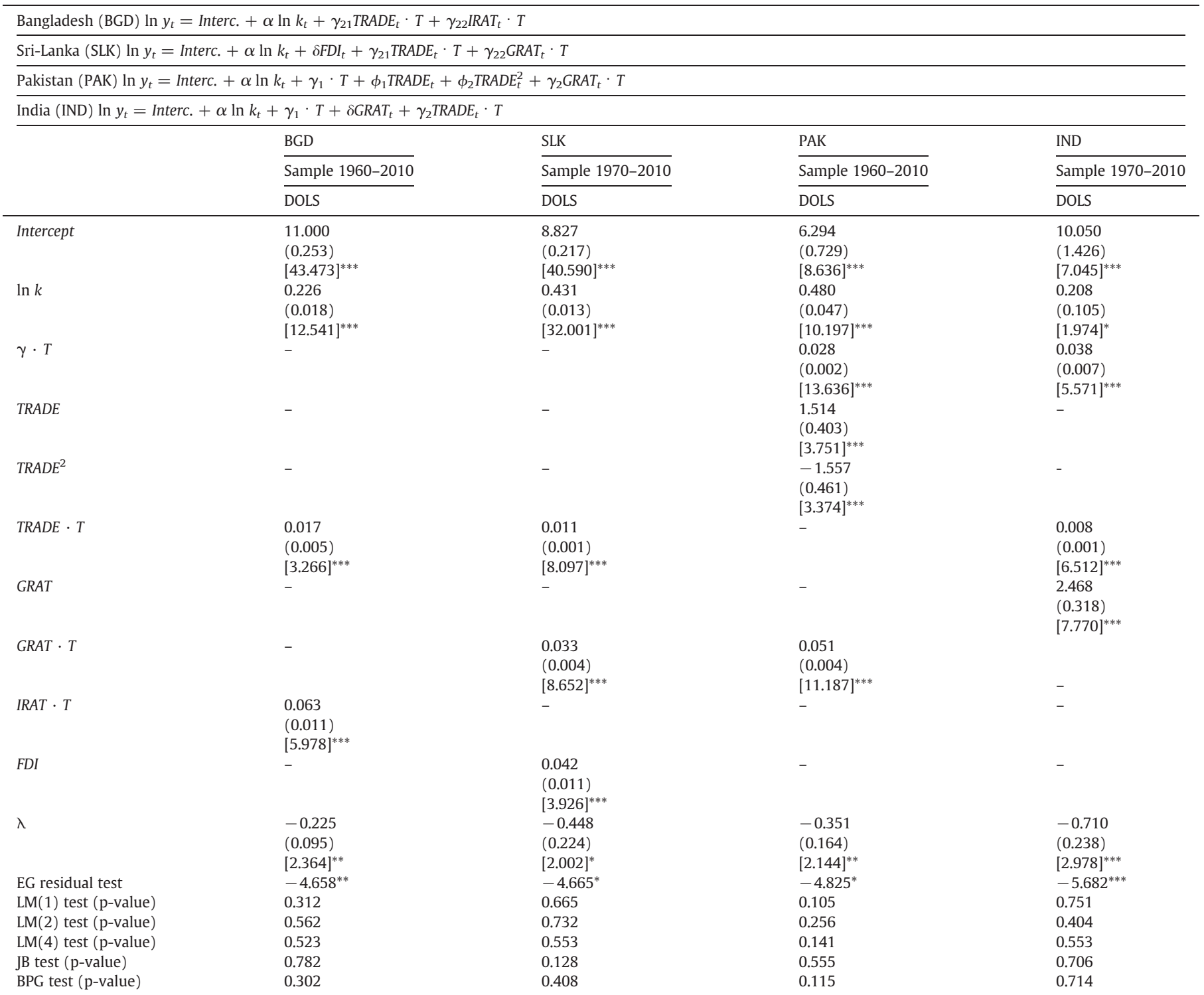

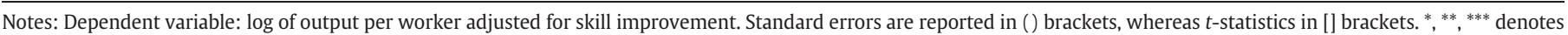

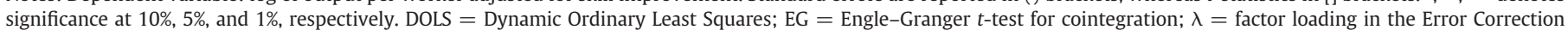

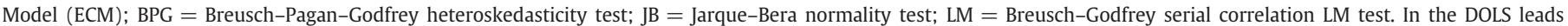

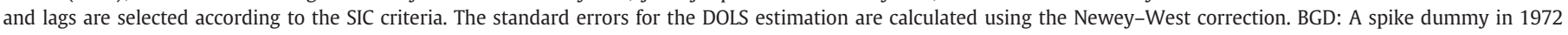

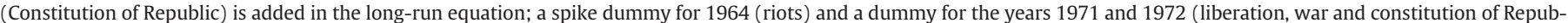

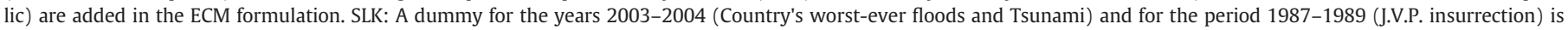

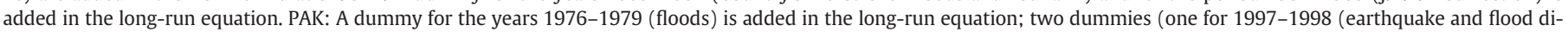

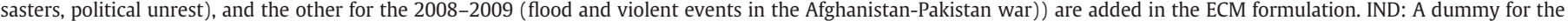

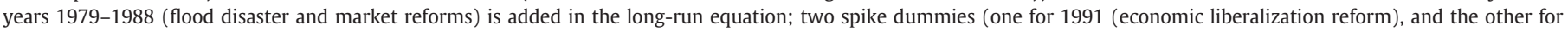
the 1979 (flood disaster)) are added in the ECM formulation.

compared to other asymptotically efficient estimators (see Inder, 1993 and Montalvo, 1995).

\section{Empirical results}

The results for Eq. (11) for the countries are reported in Table 2. In order to conserve space, we report only the best and more plausible results in terms of coefficient signs and magnitude (in particular for the elasticity of output with respect to capital $\alpha$ ), diagnostic tests, and for the signs and statistical significance of the factor loading coefficient $\lambda$ in the Error Correction Model (ECM). The diagnostic tests show that the models are correctly specified and the ECMs show a statistically significant factor loading $(\lambda)$ with the expected negative sign.
We also perform a test of stability (Quandt-Andrews structural breakpoint test ${ }^{11}$ ) on the ECM. The estimates are stable with no evidence of breaks. In addition, we run three other stability tests: the

\footnotetext{
11 The Quandt-Andrews breakpoint test (see Andrews, 1993 and Andrews and Ploberger, 1994) is widely used in the empirical literature (see for example Martin and Milas, 2012; Makin and Narayan, 2012; Petrevsky and Bogoev, 2012; Paradiso et al., 2012; Jawadi and Sousa, 2013) and tests for one or more unknown structural breakpoints in the sample for a specified equation. The idea behind this test is that a single Chow breakpoint test is performed at every observation between two observations. The test statistics from those Chow tests are then summarized into a single test statistic for a test against the null hypothesis of no breakpoints between two dates. This test checks whether there is a structural change in all of the original equation parameters.
} 
Table 3

Quandt-Andrews structural break tests for Bangladesh ECM, 1960-2010.

\begin{tabular}{llll}
\hline Statistics & Value & Break & Probability \\
\hline Max LR F-stat & 3.278 & 1971 & 0.970 \\
Max Wald F-stat & 9.833 & 1971 & 0.224 \\
Exp LR F-stat & 0.776 & - & 0.914 \\
Exp Wald F-stat & 2.832 & - & 0.185 \\
Ave LR F-stat & 1.401 & - & 0.889 \\
Ave Wald F-stat & 4.204 & - & 0.189 \\
\hline
\end{tabular}

Note: Probabilities calculated using Hansen's (1997) method.

Table 4

Quandt-Andrews structural break tests for Sri-Lanka ECM, 1970-2010.

\begin{tabular}{llll}
\hline Statistics & Value & Break & Probability \\
\hline Max LR F-stat & 1.995 & 1983 & 1.000 \\
Max Wald F-stat & 9.975 & 1983 & 0.545 \\
Exp LR F-stat & 0.623 & - & 1.000 \\
Exp Wald F-stat & 3.629 & - & 0.324 \\
Ave LR F-stat & 1.183 & - & 1.000 \\
Ave Wald F-stat & 5.915 & - & 0.277 \\
\hline
\end{tabular}

Note: Probabilities calculated using Hansen's (1997) method.

Table 5

Quandt-Andrews structural break tests for Pakistan ECM, 1960-2010.

\begin{tabular}{lrll}
\hline Statistics & Value & Break & Probability \\
\hline Max LR F-stat & 2.055 & 1980 & 1.000 \\
Max Wald F-stat & 10.276 & 1980 & 0.511 \\
Exp LR F-stat & 0.592 & - & 1.000 \\
Exp Wald F-stat & 3.214 & - & 0.425 \\
Ave LR F-stat & 1.162 & - & 1.000 \\
Ave Wald F-stat & 5.809 & - & 0.292 \\
\hline
\end{tabular}

Note: Probabilities calculated using Hansen's (1997) method.

OLS-based CUSUM test, ${ }^{12}$ the F test statistic, ${ }^{13}$ and the Bai and Perron (2003) ${ }^{14}$ test. These tests confirm that our ECM estimates are stable. These results are reported in Tables 2-7 and Fig. 1.

Increased public spending in key priority areas such as health, education and social security welfare have contributed to sustained growth ${ }^{15}$ in Sri Lanka and Pakistan. In India, GRAT has only a level effect. In Bangladesh, GRAT does not enter at all as an explanatory variable. This result for Bangladesh can be explained by high inefficiencies in the administration and usage of public resources (Ahmed, 2001). IRAT has contributed to growth in Bangladesh although its value is slightly low compared to other countries (Table 1). This can be attributed to the development of the banking sector in Bangladesh, favoring savings mobilization, and increased investment leading to development of the real sector. Trade openness enters as a driving growth enhancing variable for three countries (Bangladesh, Sri-Lanka and India). This is the result of the formation of the South Asian Association of Regional Cooperation (SAARC) in 1985 and subsequent South Asian Preferential Trade Area (SAPTA Agreement) adopted by South Asian countries with the aim of promoting trade and regional cooperation. The exception is

\footnotetext{
12 The OLS-based CUSUM test is a structural change test on cumulative residuals of the common OLS residuals (Ploberger and Kramer, 1992).

13 The F test statistic is an extension of the Chow test and calculates the F statistic for all potential change points in an interval; this test is rejected if these statistics get too large.

${ }^{14}$ This method, for a given $m$ breakpoint, tests for the single added breakpoint that most reduces the sum-of-squares. The test is run on all factor loading coefficients and the constant for all the ECM of the countries. By default, the test allows for a maximum number of 5 breaks, employing a trimming percentage of $15 \%$, and uses the 0.05 level of significance for sequential testing. In our case (Table 7), the sequential test indicates that there is one breakpoint, but this break is not statistically significant because the F-statistic, along with the F-statistic scaled by the number of varying regressors, are below the critical value for all countries.

${ }^{15}$ The positive contribution of public spending is further favored by low taxes-GDP-ratio in these countries that has reduced the negative effects on private activity (Jha, 2011).
}

Table 6

Quandt-Andrews structural break tests for India ECM, 1970-2010.

\begin{tabular}{lrll}
\hline Statistics & Value & Break & Probability \\
\hline Max LR F-stat & 2.706 & 1977 & 1.000 \\
Max Wald F-stat & 10.826 & 1977 & 0.301 \\
Exp LR F-stat & 0.897 & - & 0.980 \\
Exp Wald F-stat & 3.877 & - & 0.152 \\
Ave LR F-stat & 1.744 & - & 0.955 \\
Ave Wald F-stat & 6.978 & - & 0.072 \\
\hline
\end{tabular}

Note: Probabilities calculated using Hansen's (1997) method.

Table 7

Multiple breakpoint tests (Bai-Perron test).

\begin{tabular}{lllll}
\hline Country & Break Test & F-statistic & Scaled F-statistic & Critical value $^{\mathrm{a}}$ \\
\hline Bangladesh & 0 vs. 1 & 4.368 & 8.737 & 11.47 \\
Sri-Lanka & 0 vs. 1 & 4.871 & 9.743 & 11.47 \\
Pakistan & 0 vs. 1 & 1.505 & 3.009 & 11.47 \\
India & 0 vs. 1 & 3.171 & 6.342 & 11.47 \\
\hline
\end{tabular}

Note:

a Bai and Perron (2003) critical values.

Pakistan where TRADE enters as a non-linear level variable (see Fig. 2 for a plot of the nonlinearity effect). Non-linearity suggests that openness has a positive effect on output until a certain level, and beyond this value it produces negative effects. This may be explained by the poorer quality of institutions (defined by a society's enforced law and regulations protecting property rights) in Pakistan compared to other South Asian countries as defined by the governance index constructed by Kaufmann et al. (2010). ${ }^{16}$ This implies that when openness reaches high values, the quality of institutions have not reached levels that are required to protect and diffuse new ideas and skills stemming from stronger interaction with foreign firms.

FDI enters (even if only as level effect) as a factor influencing output in Sri-Lanka due to higher educational levels compared to the other three countries (Borensztein et al., 1998). For Pakistan and India, growth remains partially unexplained (i.e., determined by other factors not considered).

\section{Conclusion}

We investigate the growth enhancing variables in a group of selected South Asian countries (India, Sri Lanka, Pakistan and Bangladesh) over the period 1960-2010. Apart from their geographical proximity and homogeneity with respect to economic features, they also share a common history. We find, however, that contrary to what is maintained by some authors, this does not necessarily imply homogeneity. We investigate the presence of this homogeneity using appropriate statistical tests. The tests show that these countries are dissimilar. This is due to differences in institutions and national policies. Our results show that empirical studies should focus more on country-specific time-series, in particular if the aim is to suggest appropriate policy measures for sustaining growth. However, we do not argue that cross-country studies are not useful. Countries with common stylized facts can be studied together as a first stage, since it is expected that belonging to the same region, these countries share some common characteristics in any case. In addition, this is the sole method if we do not have sufficient time-series data.

Our results suggest that time-series econometrics are preferable to identifying growth drivers for a country accurately. If countryspecific investigation has this important advantage with respect to cross-country studies, in detecting the appropriate growth enhancing

\footnotetext{
16 The estimates of this index ranges from approximately -2.5 (weak) to 2.5 (strong). Unfortunately, it is not possible to conduct empirical work employing this measure of institutions due to the short sample period available (1996-2010). Additionally, there is no consensus on the definition and measurement of institutions in the literature (see for example Tebaldi and Elmslie, 2008).
} 
OLS-based CUSUM test BGD

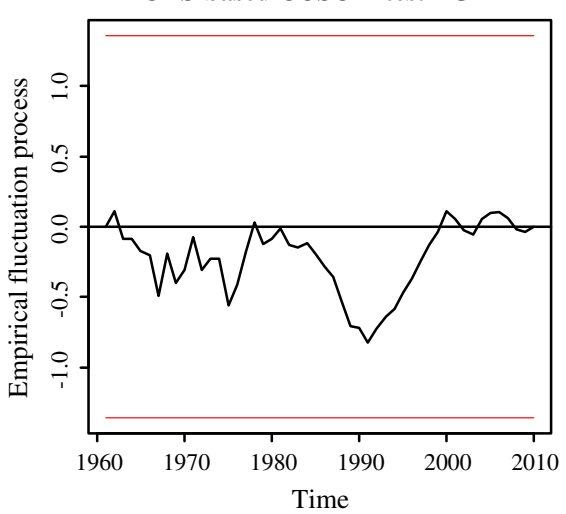

OLS-based CUSUM test SLK

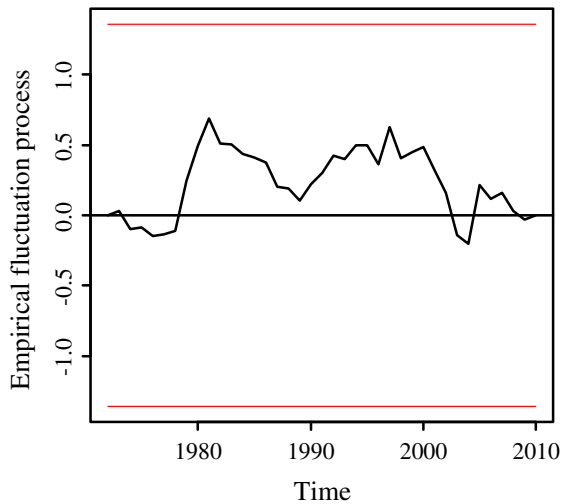

OLS-based CUSUM test PAK

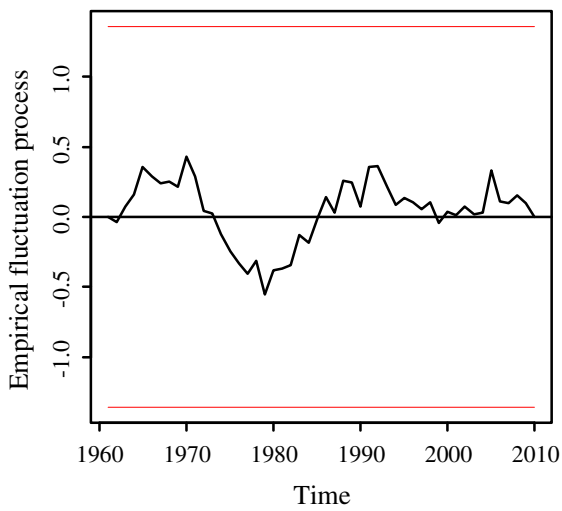

OLS-based CUSUM test IND

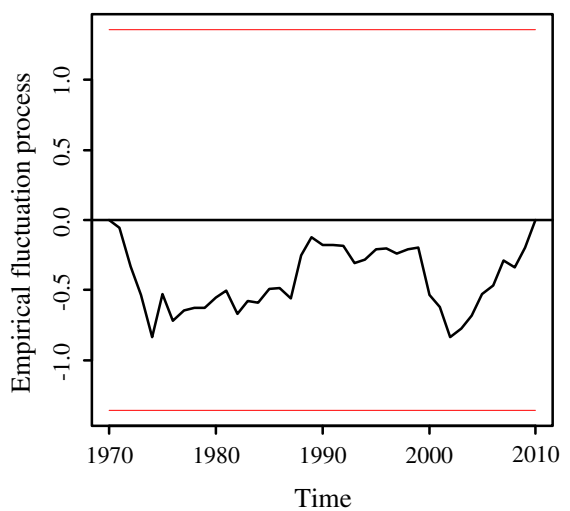

Note: The red lines indicate the boundaries.
F-statistics for all potential breaks - BGD

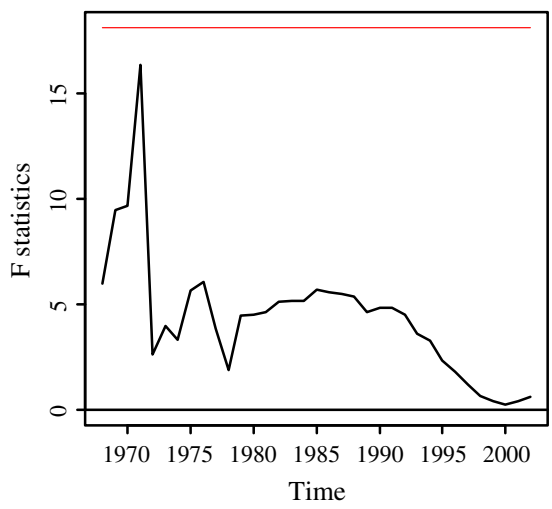

F-statistics for all potential breaks - SLK

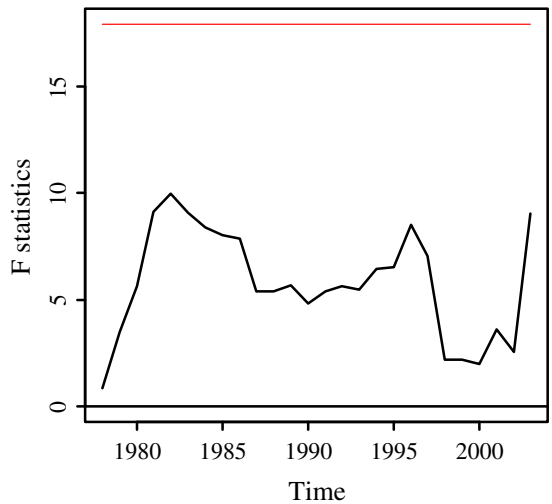

F-statistics for all potential breaks - PAK

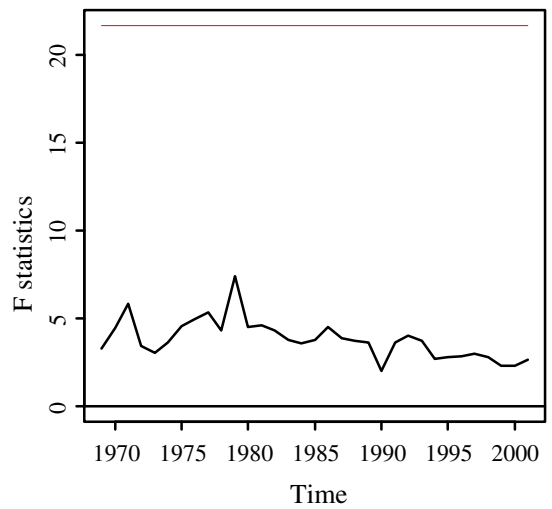

F-statistics for all potential breaks - IND

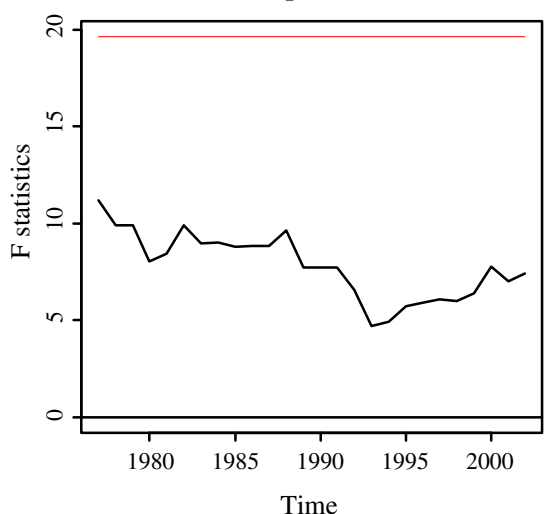

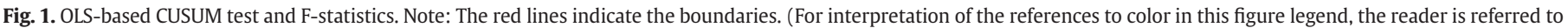
the web version of this article.) 


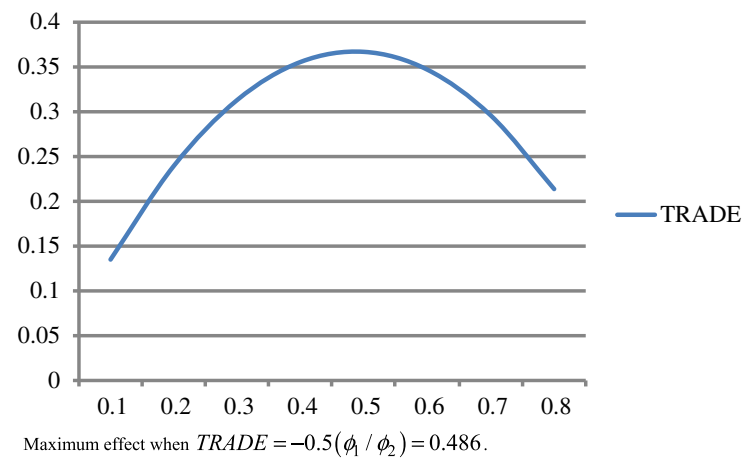

Fig. 2. Non-linear level effect of trade openness in Pakistan. Maximum effect when TRADE $=-0.5\left(\phi_{1} / \phi_{2}\right)=0.486$.

variables, why does the literature focus more on cross-country investigations? The answer is that cross-country studies have some advantages over time time-series analysis. First, cross-country studies may consider the average growth rate over long time periods, for example ten years, to estimate the effect of some variables on the growth rate. This technique eliminates the effect of business cycles that may influence the fluctuation of economic variables at higher frequency. In addition, taking the average growth rate over long time periods reduce the risk of structural breaks. Second, data are available for several countries only for short time periods of time, whereas country-specific time-series techniques require data over a long time span. All these advantages of cross-country studies are expected to vanish over the years, since econometric estimation techniques and the availability of good quality data (also for developing countries) are improving helping to solve these drawbacks of country-specific time series studies.

While policy needs to be implemented according to country specific characteristics, the general implications stemming from this study can be summarized as follows. The results suggest that trade openness is an important growth enhancing variable for all countries with exception of Pakistan where this variable has only a level effect on output (i.e., it can raise the economy's income level permanently but it has only a transitory growth effect). Bangladesh, Sri-Lanka and India should take measures to improve openness to sustain the growth in the long-run. For example, our estimates show that for Bangladesh a rise in trade openness of $1 \%$ implies a growth effect of $0.02 \%$. This implies that a $0.1 \%$ increase in long-run GDP growth requires a five percentage point increase in openness (openness is the average share of exports and imports to GDP). Similar arguments apply to Sri-Lanka and India. A 1\% increase in openness implies a growth effect of $0.01 \%$. Although these countries have opened up, its export performance is far below East Asia's (with the exception of Japan). Policies aimed at improving exports are necessary for promoting growth. Currently regional borders are constraining South Asia's growth due to inefficient trade routes. Satisfying trade restrictions in South Asia takes in average 30 days as opposed to 20 days in Latina America and 11 days for the OECD (Guerrero, 2012). The lack of proper infrastructure and management systems has increased costs and reduced trade competitiveness. The removal of barriers to trade if accompanied by complementary reforms such as financial sector development, human capital and infrastructure development will accelerate growth (Chang et al., 2009). Government expenditure is an important driver of growth in Sri Lanka and Pakistan. For these countries, policies designed to protect and enforce expenditures in social sectors and infrastructure are needed to promote faster growth. Private investment expenditure enters as a growth enhancing variable for Bangladesh. Policies designed to support and encourage private investment is necessary to stimulate long-run growth in Bangladesh. There is a need for fiscal consolidation and government expenditure restructuring to prevent the private sector from being crowded out.

\section{Acknowledgments}

We wish to thank two anonymous referees, Raghbendra Jha, Amnon Levy, Jakob Madsen, Willi Semmler and David Weil for valuable comments.

\section{References}

Ahmed, N., 2001. Parliament and Public Spending in Bangladesh. Bangladesh Institute of Parliamentary Studies (BIPS), Dhaka.

Andrews, D.W.K., 1993. Tests for parameter instability and structural change with unknown change point. Econometrica 61, 821-856.

\section{Appendix A}

Table 1A

Unit root test results.

\begin{tabular}{|c|c|c|c|c|c|c|c|c|}
\hline \multirow[b]{2}{*}{ Variable } & \multicolumn{2}{|c|}{$\begin{array}{l}\text { BGD } \\
\text { Sample 1960-2010 }\end{array}$} & \multicolumn{2}{|c|}{$\begin{array}{l}\text { SLK } \\
\text { Sample 1970-2010 }\end{array}$} & \multicolumn{2}{|c|}{$\begin{array}{l}\text { PAK } \\
\text { Sample 1960-2010 }\end{array}$} & \multicolumn{2}{|c|}{$\begin{array}{l}\text { IND } \\
\text { Sample 1970-2010 }\end{array}$} \\
\hline & $\mathrm{ADF}$ & DF-GLS & $\mathrm{ADF}$ & DF-GLS & $\mathrm{ADF}$ & DF-GLS & $\mathrm{ADF}$ & DF-GLS \\
\hline $\ln y$ & -1.85 & -1.71 & -2.44 & -2.50 & -1.38 & -1.27 & -2.01 & -1.46 \\
\hline$\Delta \ln y$ & $-5.28^{* * *}$ & $-4.09^{* * *}$ & $-4.16^{* *}$ & $-3.98^{* * *}$ & $-6.80^{* * *}$ & $-6.86^{* * *}$ & $-6.93^{* * *}$ & $-7.10^{* * *}$ \\
\hline $\ln k$ & -2.37 & -1.85 & -0.62 & -1.85 & -2.91 & -0.85 & -0.89 & -2.14 \\
\hline$\Delta \ln k$ & $-4.05^{* *}$ & $-3.65^{* *}$ & $-3.62^{* *}$ & $-2.95^{*}$ & $-4.46^{* * *}$ & $-4.31^{* * *}$ & $-3.54^{* *}$ & $-2.92^{*}$ \\
\hline TRADE & -1.40 & -1.47 & $-3.39^{*}$ & -1.76 & -1.44 & -2.17 & -0.94 & -0.96 \\
\hline$\triangle T R A D E$ & $-7.02^{* * *}$ & $-6.38^{* * *}$ & $-3.55^{* *}$ & $-3.31^{* *}$ & $-6.66^{* * *}$ & $-6.79^{* * *}$ & $-7.59^{* * *}$ & $-7.66^{* * *}$ \\
\hline IRAT & -2.47 & -2.09 & -1.70 & -1.68 & -2.81 & -2.59 & -1.57 & -1.52 \\
\hline$\triangle I R A T$ & $-6.34^{* * *}$ & $-6.46^{* * *}$ & $-5.53^{* * *}$ & $-5.68^{* * *}$ & $-6.76^{* * *}$ & $-3.58^{* *}$ & $-5.78^{* * *}$ & $-5.89^{* * *}$ \\
\hline GRAT & -1.11 & -2.84 & -1.23 & -1.63 & -2.22 & -2.29 & -1.70 & -1.52 \\
\hline$\triangle G R A T$ & $-4.66^{* * *}$ & $-5.61^{* * *}$ & $-8.95^{* * *}$ & $-8.44^{* * *}$ & $-9.21^{* * *}$ & $-9.15^{* * *}$ & $-5.14^{* * *}$ & $-5.27^{* * *}$ \\
\hline FDIRAT & 1.90 & -1.34 & -2.81 & -2.86 & -2.16 & -2.19 & -2.87 & -2.78 \\
\hline$\triangle F D I R A T$ & $-6.72^{* * *}$ & $-6.60^{* * *}$ & $-6.79^{* * *}$ & $-6.97^{* * *}$ & $-4.56^{* * *}$ & $-4.55^{* * *}$ & $-7.94^{* * *}$ & $-5.24^{* * *}$ \\
\hline ODARAT & -0.69 & -1.27 & -1.97 & -1.75 & -3.10 & $-3.15^{*}$ & $-3.51^{*}$ & -2.49 \\
\hline$\triangle O D A R A T$ & $12.94^{* * *}$ & $-3.81^{* * *}$ & $-8.54^{* * *}$ & $-8.77^{* * *}$ & $-7.00^{* * *}$ & $-7.09^{* * *}$ & $-6.03^{* * *}$ & $-4.63^{* * *}$ \\
\hline WRRAT & -0.65 & -1.54 & -2.23 & -1.71 & -2.16 & -1.76 & -2.07 & -2.12 \\
\hline$\triangle W R R A T$ & $-4.26^{* * *}$ & $-4.12^{* * *}$ & $-3.87^{* *}$ & $-3.93^{* * *}$ & $-5.42^{* * *}$ & $-4.60^{* * *}$ & $-4.49^{* * *}$ & $-4.31^{* * *}$ \\
\hline$M 2 R A T$ & -0.95 & -1.60 & -3.12 & -2.84 & -2.59 & -2.60 & -2.43 & -2.48 \\
\hline$\triangle M 2 R A T$ & $-4.65^{* * *}$ & $-4.41^{* * *}$ & $-4.63^{* * *}$ & $-4.47^{* * *}$ & $-6.42^{* * *}$ & $-6.54^{* * *}$ & $-4.45^{* * *}$ & $-4.00^{* * *}$ \\
\hline INFL & -2.44 & $-1.74^{*}$ & $-2.70^{*}$ & -1.15 & $-2.65^{*}$ & $-1.72^{*}$ & $-2.77^{*}$ & -0.24 \\
\hline$\triangle I N F L$ & $-10.89^{* * *}$ & $-10.61^{* * *}$ & $-6.91^{* * *}$ & $-5.84^{* * *}$ & $-7.40^{* * *}$ & $-7.22^{* * *}$ & $-3.82^{* * *}$ & $5.06^{* * *}$ \\
\hline
\end{tabular}

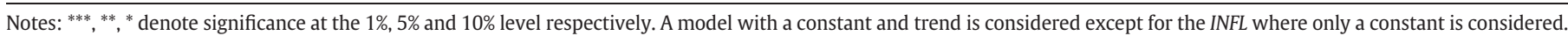

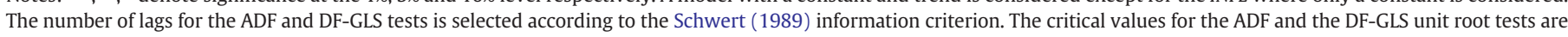
tabulated in MacKinnon (1996) and Elliot et al. (1996) respectively. 
Andrews, D.W.K., Ploberger, W., 1994. Optimal tests when a nuisance parameter is present only under the alternative. Econometrica 62, 1383-1414.

Bai, J., Perron, P., 2003. Computation and analysis of multiple structural change models. Journal of Applied Econometrics 18, 1-22.

Balasubramanyam, V., Salisu, M., Sapsford, D., 1996. Foreign Direct Investment in EP and IS Countries. The Economic Journal 106, 92-105.

Barro, R., 1996. Inflation and Growth. Federal Reserve Bank of Saint Louis (May/June).

Barro, R., Lee, J., 2010. A new data set of education attainment in the world, 1950-2010. NBER Working Paper No. 15902.

Bergheim, S., 2008. Long-run Growth Forecasting. Springer-Verlag, Berlin, Germany.

Borensztein, E., De Gregorio, J., Lee, J.-W., 1998. How does foreign direct investment affect economic growth? Journal of International Economics 45, 115-135.

Breusch, T., Pagan, A., 1980. The Lagrange multiplier test and its applications to model specification in econometrics. The Review of Economic Studies 47, 239-253.

Burnside, C., Dollar, D., 2000. Aid, policies and growth. American Economic Review 90, 847-868.

Canova, F., 2004. Testing for convergence clubs in income per capita: a predictive density approach. International Economic Review 45, 49-77.

Casadio, P., Paradiso, A., Rao, B.B., 2012. Estimates of the steady state growth rates for some European countries. Economic Modelling 29, 1119-1125.

Chang, R., Kaltani, L., Loayza, N., 2009. Openness can be good for growth: the role of policy complementarities. Journal of Development Economics 90, 33-49.

Coakley, J., Fuertes, A., Smith, R., 2006. Unobserved heterogeneity in panel time series models. Computational Statistics and Data Analysis 50, 2361-2380.

Cooray, A., 2012. The impact of migrant remittances on economic growth: evidence from South Asia. Review of International Economics 20, 985-998.

Desdoigts, A., 1999. Patterns of economic development and the formation of clubs. Journal of Economic Growth 4, 305-330.

Dinopoulos, E., Thompson, P., 1999. Reassessing the empirical validity of the human capital augmented neoclassical growth model. Journal of Evolutionary Economics 9, $135-154$.

Durlauf, S.N., Johnson, P.A., 1995. Multiple regimes and cross-country growth behaviour Journal of Applied Econometrics 10, 365-384.

Durlauf, S.N., Quah, D.T., 1999. The new empirics of economic growth. In: Taylor, J.B. Woodford, M. (Eds.), Handbook of Macroeconomics. Elsevier Science, Amsterdam, pp. 235-308.

Durlauf, S., Kourtellos, A., Minkin, A., 2001. The local Solow growth model. European Economic Review 45, 928-940.

Elliot, G., Rothenberg, T., Stock, J., 1996. Efficient tests for an autoregressive unit root Econometrica 64, 813-836.

Greiner, A., Semmler, W., Gong, G., 2005. The Forces of Economic Growth: A Time Series Perspective. Princeton University Press, Princeton.

Guerrero, I., 2012. What if Trade Barriers were reduced in South Asia, Express Tribune, PK: Himalayan Times, NP; Economic Times, IN; Financial Express, BD; Financial Times, SL, October 10, 2012

Hansen, B.E., 1997. Approximate asymptotic p-values for structural-change tests Journal of Business and Economic Statistics 15, 60-67.

Inder, B., 1993. Estimating long-run relationships in economics. Journal of Econometrics $57,53-68$.

Jakobi, A.P., Teltemann, J., 2009. Convergence and divergence in welfare state development: an assessment of education policy in OECD countries. TranState working papers No. 93 .

Jalles, J.T., 2012. Openness, regional trade agreements and growth: evidence from Asia. Asian Economic Journal 26, 63-85.

Jawadi, F., Sousa, R.M., 2013. Structural breaks and nonlinearity in US and UK public debts. Applied Economics Letters 2013 (20), 653-657.

Jha, R., 2011. Fiscal policies and challenges in South Asia. In: Jha, R. (Ed.), Routledge Handbook of South Asian Economics. Routledge, London and New York, pp. 171-181.

Jongwanich, J., Kohpaiboon, A., 2013. Capital flows and real exchange rates in emerging Asian countries. Journal of Asian Economics 24, 138-146.

Kaufmann, D., Kraay, A., Mastruzzi, M., 2010. The Worldwide Governance indicators: methodology and analytical issues. World Bank Policy Research Working Paper No. 5430.The World Bank, Washington, DC.

Kholi, I., Singh, N., 1989. Exports and growth: critical minimum effort and diminishing returns. Journal of Development Economics 30, 391-400.

King, R., Levine, R., 1993. Finance and growth: Schumpeter might be right. Quarterly ournal of Economics 108, 717-738.
King, A., Ramlogan, C., 2008. Is Latin America catching up? A time-series approach. Review of Development Economics 12, 397-415.

Kumar, S., Pacheco, G., 2012. What determines the long run growth rate in Kenya? Journal of Policy Modelling. http://dx.doi.org/10.1016/j.jpolmod.2012.01.009.

Levene, H., 1960. Robust tests for equality of variances. In: Olkin, I., Ghurye, S.G., Hoeffding, W., Madow, W.G., Mann, H.B. (Eds.), Contributions to Probability and Statistics. Essays in honor of Harold Hotelling. Stanford University Press, Stanford, pp. 278-292.

Luintel, K., Khan, M., Arestis, P., Theodoridis, K., 2008. Financial structure and economic growth. Journal of Development Economics 86, 181-200

MacKinnon, J.G., 1996. Numerical distribution functions for unit root and cointegration tests. Journal of Applied Econometrics 11, 601-618.

Makin, A.J., Narajan, P.K., 2012. Re-examining the "twin deficits" hypothesis: evidence from Australia. Empirical Economics 1-13. http://dx.doi.org/10.1007/s00181-0120628-7 (August 2012).

Mallik, G., Chowdhury, A., 2001. Inflation and economic growth: evidence from four South Asian countries. Asian-Pacific Development Journal 18, 123-135.

Mankiw, N.G., Romer, D., Weil, D.W., 1992. A contribution to the empirics of economic growth. Quarterly Journal of Economics 107, 407-437.

Martin, C., Milas, C., 2012. Financial crises and monetary policy: evidence from the UK. Journal of Financial Stability 1-8. http://dx.doi.org/10.1016/j.jfs.2012.08.002 (September 2012).

Montalvo, J.G., 1995. Comparing cointegrating regression estimators: some additional Monte Carlo results. Economics Letters 48, 229-234.

Narayan, S., Narayan, P.K., Mishra, S., 2010. Investigating the relationship between health and economic growth: empirical evidence from a panel of 5 Asian countries. Journal of Asian Economics 21, 404-411.

Paradiso, A., Kumar, S., Rao, B.B., 2012. The growth effects of education in Australia. Applied Economics 45, 3843-3852.

Parra-Frutos, I., 2009. The behaviour of the modified Levene's test when data are not normally distributed. Computational Statistics 24, 671-693.

Petrevsky, G., Bogoev, J., 2012. Interest rate pass-through in South East Europe: an empirical analysis. Economic Systems 36, 571-593.

Pianta, M., 1995. Technology and growth in OECD countries, 1970-1990. Cambridge Journal of Economics 19, 175-187.

Ploberger, W., Kramer, W., 1992. The CUSUM test with OLS residuals. Econometrica 60, 271-285.

Plourde, A., Watkins, G.C., 1998. Crude oil prices between 1985 and 1994: how volatile in relation to other commodities? Resource and Energy Economics 20, 245-262.

Rao, B.B., 2010. Time-series econometrics of growth-models: a guide for applied economists. Applied Economics 42, 73-86.

Rao, B.B., Hassan, G.M., 2012a. Are the direct and indirect growth effects of remittances significant? The World Economy 35, 351-372.

Rao, B.B., Hassan, G.M., 2012b. An analysis of the determinants of the long-run growth rate of Bangladesh. Applied Economics 44, 565-580.

Rao, B.B., Tamazian, A., Vadlamannati, K.C., 2011. Growth effects of a comprehensive measure of globalization with country-specific time series data. Applied Economics 43, 551-568.

Rizavi, S.S., Khan, M.K., Mustafa, S.H., 2010. Openness and growth in South Asia. South Asian Studies 25, 419-428.

Roberts, J., 2003. Poverty reduction outcomes in education and health public expenditure and aid. Overseas Development Institute Working Paper No. 210.

Saikkonen, P., 1991. Asymptotically efficient estimation of cointegration regressions. Econometric Theory 7, 1-21.

Sala-i-Martin, X., 1994. Lecture notes on economic growth (I): introduction to the literature and neoclassical models. Economics Working Paper 77.Department of Economics and Business, Universitat Pompeu Fabra.

Schwert, G.W., 1989. Tests for unit roots: a Monte Carlo investigation. Journal of Business and Economic Statistics 7, 147-159.

Senhadji, A., 2000. Sources of economic growth: an extension growth accounting exercise. IMF Staff Papers 47, 129-157.

Starke, P., Obinger, H., Castles, F.G., 2008. Convergence towards where: in what ways, if any, are welfare States becoming more similar? Journal of European Public Policy $15,975-1000$

Tebaldi, E., Elmslie, B., 2008. Do institutions impact innovation? MPRA Working Paper No. 8757.Munich University Library, Munich. 